\title{
Protective Effects of a Novel Lactobacillus brevis Strain with Probiotic Characteristics against Staphylococcus aureus Lipoteichoic Acid-Induced Intestinal Inflammatory Response
}

\author{
Won-Ju Kim, Jun-Hyun Hyun, Na-Kyoung Lee, and Hyun-Dong Paik* \\ Department of Food Science and Biotechnology of Animal Resources, Konkuk University, Seoul 05029, Republic of \\ Korea
}

Probiotics can effectively modulate host immune responses and prevent gastrointestinal diseases. The objective of this study was to investigate the probiotic characteristics of Lactobacillus brevis KU15152 isolated from kimchi and its protective potential against intestinal inflammation induced by Staphylococcus aureus lipoteichoic acid (aLTA). L. brevis KU15152 exhibited a high survival rate in artificial gastric and bile environments. Additionally, the adhesion capability of the strain to HT-29 cells was higher than that of $L$. rhamnosus GG. L. brevis KU15152 did not produce harmful enzymes, such as $\beta$-glucuronidase, indicating that it could be used as a potential probiotic. The antiinflammatory potential of $L$. brevis KU15152 was determined in HT-29 cells. Treatment with $L$. brevis KU15152 suppressed the production of interleukin-8 without inducing significant cytotoxicity. The downregulatory effects of $L$. brevis KU15152 were involved in the suppression of nuclear factorkappa B activation mediated by the extracellular signal-regulated kinase and Akt signaling pathways. Collectively, these data suggest that $L$. brevis KU15152 can be used in developing therapeutic and prophylactic products to manage and treat aLTA-induced intestinal damage.

Keywords: Probiotics, anti-inflammatory, HT-29 cell, ERK signaling, Akt signaling

Received: October 21, 2021 Accepted: November 4, 2021

First published online: November 6, 2021

*Corresponding author Phone: +82-2-2049-6011 E-mail: hdpaik@konkuk.ac.kr

pISSN 1017-7825 elSSN 1738-8872

Copyright (C) 2022 by the authors. Licensee KMB. This article is an open access article distributed under the terms and conditions of the Creative Commons Attribution (CC BY) license.

\section{Introduction}

The human gut microbiota comprises trillions of microorganisms. This microbiota is essential for nutrient absorption, gut barrier function, and immunomodulation [1]. Lipopolysaccharide (LPS) or proinflammatory cytokines stimulate intestinal epithelial cells, resulting in intestinal inflammation. Gut microbiota act as barriers against external stimulation bacteria. Aberrant microbiota can allow the invasion of pathogenic bacteria, leading to the activation of a damaging immune response and various intestinal disorders [2]. Lipoteichoic acid (LTA) is a cell wall component of gram-positive bacteria. LTA is considered comparable to LPS, because of its physiological and biochemical properties. Inflammatory responses can be triggered by either LPS or LTA, resulting in tissue damage and organ failure [3]. However, immunomodulatory effects of LTAs from different strains can be distinct [4].

Probiotics are live microorganisms that are beneficial to host health when ingested in adequate amounts. As natural inhabitants of gut, probiotics can modulate the microflora and protect the gut against invading pathogens [5]. Probiotics maintain mucosal or systemic immune responses and promote barrier function [6]. In addition, probiotics can downregulate the expression of proinflammatory cytokines and ameliorate intestinal inflammatory diseases by suppressing nuclear factor-kappa $\mathrm{B}(\mathrm{NF}-\mathrm{\kappa B})$ signaling pathway $[7,8]$.

Recent studies have focused on the functions of lactic acid bacteria (LAB), including Lactobacillus sp., Lactococcus sp., Weissella sp., and Leuconostoc sp., which are the dominant strains in the microflora of kimchi, a traditional Korean fermented food $[9,10]$. Kimchi is recognized as contributing to the health of individuals. During fermentation, LAB strains produce the unique flavor of kimchi and lactic acid, which decreases the $\mathrm{pH}$ of the product [11]. Several LAB strains have probiotic characteristics and various beneficial properties such as antioxidant, antimicrobial, and immunostimulatory activities [12]. In particular, they participate in the maintenance and modulation of homeostasis in the intestinal immune system [13]. Lactobacillus species regulate inflammatory responses by inhibiting interleukin (IL)- 8 production and NF- $\kappa$ B activation in intestinal epithelial cells [14]. The present study aimed to investigate the probiotic potential of a novel Lactobacillus strain, L. brevis KU15152, and the effects of the strain in alleviating Staphylococcus aureus lipoteichoic acid (aLTA)-induced intestinal inflammatory responses. 


\section{Materials and Methods}

Chemicals and Reagents

De Man, Rogosa, and Sharpe (MRS) medium was purchased from Difco Laboratories (USA). Roswell Park Memorial Institute (RPMI) 1640 medium, antibiotics solution, and phosphate-buffered saline (PBS) were obtained from HyClone Laboratories, Inc. (USA). Fetal bovine serum (FBS) was purchased from Life Technologies (USA). Equipment and reagents for western blotting were purchased from Bio-Rad (USA). Other chemicals including aLTA were purchased from Sigma-Aldrich (USA).

\section{Bacterial Strains and Cell Culture Conditions}

L. brevis KU15152 was isolated from Chonggak kimchi. L. rhamnosus GG (LGG), used for comparative analysis, was obtained from the Korean Collection for Type Cultures (Korea). L. brevis KU15153 was used as a comparative strain owing to its anti-inflammatory effects [15]. To evaluate the protective effect of these strains, L. brevis strains and LGG were incubated in MRS at $37^{\circ} \mathrm{C}$ for $18 \mathrm{~h}$. The bacteria were recovered by centrifugation $\left(12,000 \times g, 4^{\circ} \mathrm{C}, 5 \mathrm{~min}\right)$, washed twice with PBS, and suspended in RPMI 1640 medium at 7 log colony forming units $(\mathrm{CFU}) / \mathrm{ml}$. These are defined as the bacterial sample.

HT-29 cells obtained from the Korean Cell Line Bank (Korea) were cultured in RPMI 1640 medium supplemented with $10 \% \mathrm{FBS}$ and $1 \%$ penicillin-streptomycin solution. Cells were maintained at $37^{\circ} \mathrm{C}$ in a $5 \%$ $\mathrm{CO}_{2}$-containing humidified atmosphere and sub-cultured at $70-80 \%$ confluency.

\section{Tolerance to Artificial Gastric Juice and Bile Salts}

The tolerance of Lactobacillus strains to gastrointestinal conditions was determined as previously described [11]. Briefly, L. brevis KU15152 and LGG were pre-cultured overnight in MRS medium. To determine their resistance to artificial gastric juice and bile salts, these strains were incubated in MRS broth containing $0.3 \%$ (w/v) pepsin ( $\mathrm{pH} 2.5$ ) for $3 \mathrm{~h}$, and MRS broth with $0.3 \%$ (w/v) oxgall for $24 \mathrm{~h}$, respectively. The survival rate (\%) of the strains was calculated as follows:

$$
\text { Survival rate }(\%)=\frac{\text { Cell number after incubation }(\log \mathrm{CFU} / \mathrm{ml})}{\text { Inoculated cell number }(\log \mathrm{CFU} / \mathrm{ml})} \times 100
$$

\section{Adhesion Ability}

Adhesion ability of the Lactobacillus strains was evaluated according to a previously described method [16] using HT-29 cells with some modifications. The cells $\left(2 \times 10^{5}\right.$ per/well $)$ were plated in 24 -well plates and incubated until a confluent monolayer was obtained. Then, the medium was replaced by antibiotic-free RPMI 1640 medium. L. brevis KU15152 or LGG (7 log CFU/ml) were added to each well and incubated for $2 \mathrm{~h}$. Non-adherent bacteria were removed by washing the wells twice with PBS. The remaining attached bacteria were collected by treatment with $0.1 \%$ Triton X-100. The adhesion ability (\%) of the strains was calculated as follows:

$$
\text { Adhesion ability }(\%)=\frac{\text { Attached bacterial cell number }(\log \mathrm{CFU} / \mathrm{ml})}{\text { Inoculated bacterial cell number }(\log \mathrm{CFU} / \mathrm{ml})} \times 100
$$

\section{Enzyme Production}

The ZYM kit (API, France) was used to analyze the enzyme production of the Lactobacillus strains, according to the manufacturer's instructions. Overnight incubated L. brevis KU15152 and LGG were diluted in PBS at 9 log $\mathrm{CFU} / \mathrm{ml}$, and then added to cupules. Following incubation for $4 \mathrm{~h}$ at $37^{\circ} \mathrm{C}$, the ZYM test reagents were added. Enzyme production was determined as the color change.

\section{Determination of Cell Viability}

The viability of HT-29 cells was determined using the 3-(4,5-dimethylthiazol-2-yl)-2,5-diphenyltetrazolium bromide (MTT) assay with modifications [17]. Briefly, HT-29 cells $\left(2 \times 10^{5}\right.$ cells/well) were seeded in 24-well plates and incubated until monolayer formation. The cells were cultured with the bacterial samples for $2 \mathrm{~h}$ with or without $50 \mu \mathrm{g} / \mathrm{ml}$ aLTA for another $22 \mathrm{~h}$. MTT solution was added to each well at a final concentration of $0.5 \mathrm{mg} / \mathrm{ml}$. The cells were incubated for $30 \mathrm{~min}$, the supernatant was discarded, and the resulting formazan deposits were dissolved in $1 \mathrm{ml}$ dimethyl sulfoxide. The absorbance of the resultant solution was estimated at $570 \mathrm{~nm}$ using Thermo Scientific Multiskan GO (Thermo Scientific, USA). Cell viability was determined as a percentage relative to the absorbance of the control groups.

\section{Measurement of IL-8 Production}

The effect of Lactobacillus strains on the production of IL- 8 was investigated in aLTA-induced HT-29 cells using an enzyme-linked immunosorbent assay kit (Thermo Fisher Scientific). HT-29 cells $\left(2 \times 10^{5}\right.$ cells/well) were plated in 24 well plates and grown until confluent monolayers were formed. The cells were pretreated with the bacterial samples. After incubation for $2 \mathrm{~h}$, cells were incubated with or without $50 \mathrm{\mu g} / \mathrm{ml}$ aLTA for an additional $22 \mathrm{~h}$. Collected cell culture supernatants were diluted appropriately with cell growth media and used to measure the amount of IL-8 according to the manufacturer's instructions.

\section{Western Blotting}

Protein expression was determined using western blotting [18]. HT-29 cells $\left(5 \times 10^{5}\right.$ cells/well $)$ were plated in 6- 
well plates and incubated until a monolayer was formed. After $2 \mathrm{~h}$ of pretreatment with the bacterial samples, the cells were left untreated or stimulated with aLTA $(50 \mu \mathrm{g} / \mathrm{ml})$ for the indicated time. The cells were rinsed with icecold PBS and lysed with Pro-Prep lysis buffer (iNtRON Biotechnology, Korea) supplemented with protease and phosphatase inhibitor cocktails. The supernatant was collected from the lysates by centrifugation $(15,000 \times g$, $\left.30 \mathrm{~min}, 4^{\circ} \mathrm{C}\right)$. Cellular proteins $(20-30 \mu \mathrm{g})$ quantified using the DC Protein Assay Kit (Bio-Rad) were separated via $10 \%$ sodium dodecyl sulfate-polyacrylamide gel electrophoresis and transferred to a polyvinyl difluoride membrane. The membranes were blocked with 5\% skim milk for $1 \mathrm{~h}$ and incubated with appropriate primary antibodies at $4^{\circ} \mathrm{C}$ overnight. Primary antibodies against phosphorylated mitogen-activated protein kinase kinase (p-MEK), extracellular signal-regulated kinase (ERK), p-ERK, Akt, p-Akt, glycogen synthase kinase (GSK) 3ß, pGSK $3 \beta$ and p65 were purchased from Cell Signaling Technology, Inc. (USA). Other primary antibodies were purchased from Santa Cruz Biotechnology (USA). The membranes were then probed with horseradish peroxidase-conjugated secondary antibodies for $2 \mathrm{~h}$, at room temperature. The enhanced chemiluminescence detection kit (Bio-Rad) was used to detect the protein bands, and the density of the protein bands was quantified using the ImageJ software (National Institutes of Health, USA).

\section{Statistical Analysis}

Experimental data are presented as mean \pm standard deviation (three replicates). IBM SPSS (Version 18.0, SPSS Inc., USA) was used for the statistical analysis. Statistical differences between two groups were analyzed using the unpaired one-tailed Student's $t$-test, and those among multiple groups, using one-way analysis of variance and Tukey's HSD test $(p<0.05)$.

\section{Results}

Tolerance to Artificial Digestive Conditions and Adhesion to HT-29 Cells

Resistance to artificial gastric juice and bile salt is necessary for LAB to function as probiotics. The tolerance to artificial digestive conditions is shown in Table 1. The survival rates of LGG and L. brevis KU15152 after exposure to artificial gastric acid ( $\mathrm{pH} 2.5,0.3 \%$ pepsin) for $3 \mathrm{~h}$ were $98.35 \%$ and $99.36 \%$, respectively. In addition, L. brevis KU15152 exhibited high tolerance to artificial bile salt conditions ( $0.3 \%$ oxgall) with a viability rate of $108.24 \%$. The rate was higher than that of LGG (100.48\%).

Adhesion to intestinal epithelial cells is an important criterion for identifying potential probiotic bacteria. The adhesion of LGG and L. brevis KU15152 to HT-29 intestinal cells was investigated (Table 1). The adhesion rates of the two strains were $12.04 \%$ and $12.92 \%$, respectively. The results implicated L. brevis KU15152 as a potential probiotic.

\section{Enzyme Production}

The enzyme production of the LAB strains was assessed using the API ZYM kit (Table 2). Compared to LGG, L. brevis KU15152 did not produce $\alpha$-galactosidase and $\mathrm{N}$-acetyl- $\beta$-glucosaminidase. However, L. brevis KU15152 produced a remarkably higher amount of $\alpha$-glucosidase, which catalytically mediates the bioconversion process. Additionally, the strain did not produce $\beta$-glucuronidase which is considered as a carcinogenic enzyme.

\section{Effect of L. brevis KU15152 on IL-8 Production in Intestinal Cells}

To investigate the effect of LTA from S. aureus (aLTA) and Lactobacillus strains with probiotic characteristics on inflammatory responses in intestinal cells, HT-29 cells were stimulated with aLTA in the presence of Lactobacillus strains. When treated with $8 \log \mathrm{CFU} / \mathrm{ml}$ L. brevis KU15152, viability was $86.97 \pm 1.60 \%$. However, none of the tested groups ( $7 \log \mathrm{CFU} / \mathrm{ml}$ ) showed significant cytotoxicity in HT-29 cells (Fig. 1A). Compared to the aLTAnegative group, treatment with $50 \mu \mathrm{g} / \mathrm{ml}$ aLTA markedly increased the production of IL-8. However, pretreatment with Lactobacillus strains suppressed the production of IL-8 (Fig. 1B). Additionally, L. brevis KU15152 exhibited the most significant downregulation of IL- 8 secretion. These findings suggest that $L$. brevis KU15152 inhibits IL8 production, compared to L. brevis KU15153 and LGG without adversely affecting cell viability.

Table 1. Tolerance of LGG and L. brevis KU15152 to artificial gastric acid and bile salts, and their adhesion to HT-29 cells.

\begin{tabular}{|c|c|c|}
\hline \multirow{2}{*}{ Treatment } & \multicolumn{2}{|c|}{ Cell number $(\log \mathrm{CFU} / \mathrm{ml})$} \\
\hline & LGG & L. brevis KU15152 \\
\hline \multicolumn{3}{|l|}{ Tolerance to artificial gastric acid and bile salt } \\
\hline Initial cell number & $8.37 \pm 0.14$ & $7.68 \pm 0.15$ \\
\hline Cell number after incubation ( $0.3 \%$ pepsin, $\mathrm{pH} 2.5,3 \mathrm{~h})$ & $8.23 \pm 0.11$ & $7.63 \pm 0.09$ \\
\hline Survival rate $(\%)$ & $98.35 \pm 2.65^{\mathrm{a}}$ & $99.36 \pm 0.81^{\mathrm{a}}$ \\
\hline Cell number after incubation ( $0.3 \%$ oxgall, $24 \mathrm{~h})$ & $8.41 \pm 0.17$ & $8.31 \pm 0.15$ \\
\hline Survival rate $(\%)$ & $100.48 \pm 1.11^{\mathrm{a}}$ & $108.24 \pm 3.74^{\mathrm{b}}$ \\
\hline \multicolumn{3}{|l|}{ Adhesion to HT-29 cells } \\
\hline Initial cell number & $8.37 \pm 0.01$ & $7.72 \pm 0.03$ \\
\hline Adherent cell number after $2 \mathrm{~h}$ & $7.44 \pm 0.05$ & $6.82 \pm 0.12$ \\
\hline Adhesion ability (\%) & $12.04 \pm 1.71^{\mathrm{a}}$ & $12.92 \pm 2.61^{\mathrm{a}}$ \\
\hline
\end{tabular}

$\overline{a, b}$ Different letters in the same row indicate statistical significance based on Tukey's HSD test $(p<0.05)$. 
Table 2. Enzyme production by LGG and L. brevis KU15152.

\begin{tabular}{lcc}
\hline \multicolumn{1}{c}{ Enzymes } & & Enzyme Activity \\
\cline { 2 - 3 } & LGG & L. brevis KU15152 \\
\hline Control & - & - \\
Esterase (C4) & + & + \\
Esterase lipase (C8) & + & + \\
Leucine arylamidase & + & + \\
Valine arylamidase & + & + \\
Cystine arylamidase & + & + \\
Acid phosphatase & + & + \\
Naphthol-AS-BI-phosphohydrolase & + & + \\
$\alpha$-Galactosidase & + & - \\
$\beta$-Galactosidase & - & + \\
$\beta$-Glucuronidase & - & + \\
$\alpha$-Glucosidase & + & - \\
N-Glucosidase & + & \\
\hline
\end{tabular}

+, Production; -, Non-production.
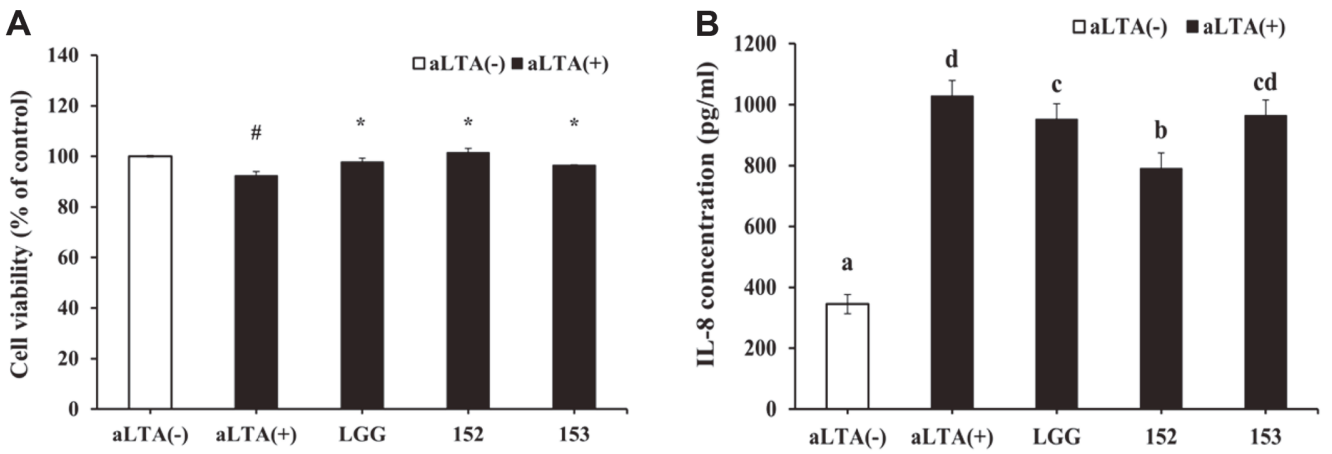

Fig. 1. Inhibitory effect of Lactobacillus strains on the production of IL-8 in HT-29 cells. Cells were incubated to achieve confluence before being stimulated with aLTA $(50 \mu \mathrm{g} / \mathrm{ml})$ in the presence of the bacterial samples for $24 \mathrm{~h}$. A. Viability of HT-29 cells examined using the MTT assay. B. IL- 8 production in aLTA-induced HT- 29 cells. \# $p<0.001$ compared with aLTA-negative group, ${ }^{\star} p<0.001$ compared with aLTA-positive group. Different letters indicate statistical differences $(p<0.05)$

Effect of L. brevis KU15152 on NF-кB Activation in Intestinal Epithelial Cells

L. brevis KU15152 suppressed the production of IL-8 in aLTA-stimulated HT-29 cells (Fig. 1). Thus, the effect of Lactobacillus strains on the activation of NF- $\mathrm{kB}$ was determined. Cells incubated with $50 \mu \mathrm{g} / \mathrm{ml}$ aLTA showed markedly increased phosphorylation of p65 compared to cells incubated in the absence of aLTA. In contrast, the phosphorylation of p65 was downregulated by pretreatment with the Lactobacillus strains (Fig. 2). In particular, L. brevis KU15152 significantly inhibited the activation of NF- $\kappa B$ in HT-29 cells, indicating that the inhibitory effect of $L$. brevis KU15152 on aLTA-induced inflammatory response was associated with the downregulation of $\mathrm{NF}-\mathrm{\kappa B}$ activation.

A

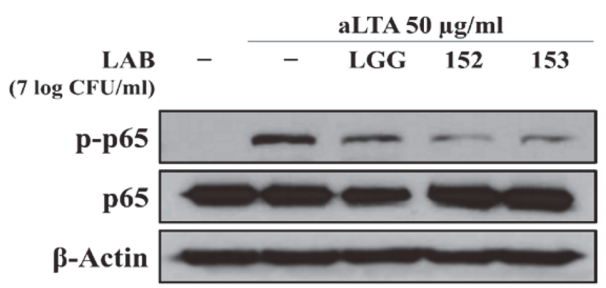

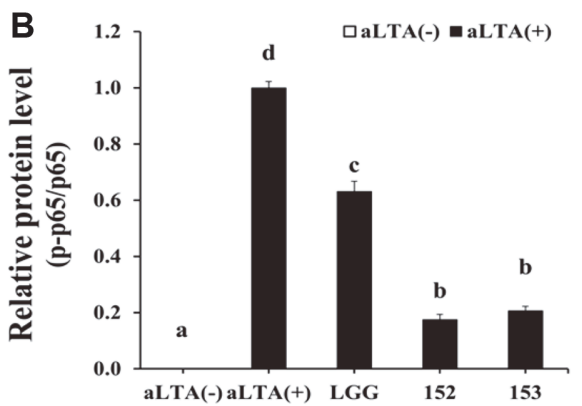

Fig. 2. Effect of Lactobacillus strains on the activation of NF-кB in HT-29 cells. Cells were cultured to form a monolayer prior to treatment with Lactobacillus strains for $2 \mathrm{~h}$. The cells were stimulated with $50 \mu \mathrm{g} / \mathrm{ml}$ of aLTA for another $12 \mathrm{~h}$. A. Protein expression levels of NF- $\mathrm{kB}$ determined using western blotting. B. Relative protein expression levels of phosphorylated p65. Different letters indicate statistical differences $(p<0.05)$. 
Effect of $L$. brevis KU15152 on MEK/ERK Signaling Pathways in HT-29 Cells

To determine the signaling mechanisms related to the effect of $L$. brevis KU15152 on the inflammatory response in intestinal epithelial cells, the expression levels of the MEK/ERK signaling-related proteins were examined (Fig. 3). Stimulation with aLTA significantly upregulated the expression of phosphorylated MEK and ERK $1 / 2$ in HT-29 cells. However, MEK and ERK 1/2 phosphorylation was alleviated by treatment with L. brevis KU15152 for $20 \mathrm{~min}$.

A
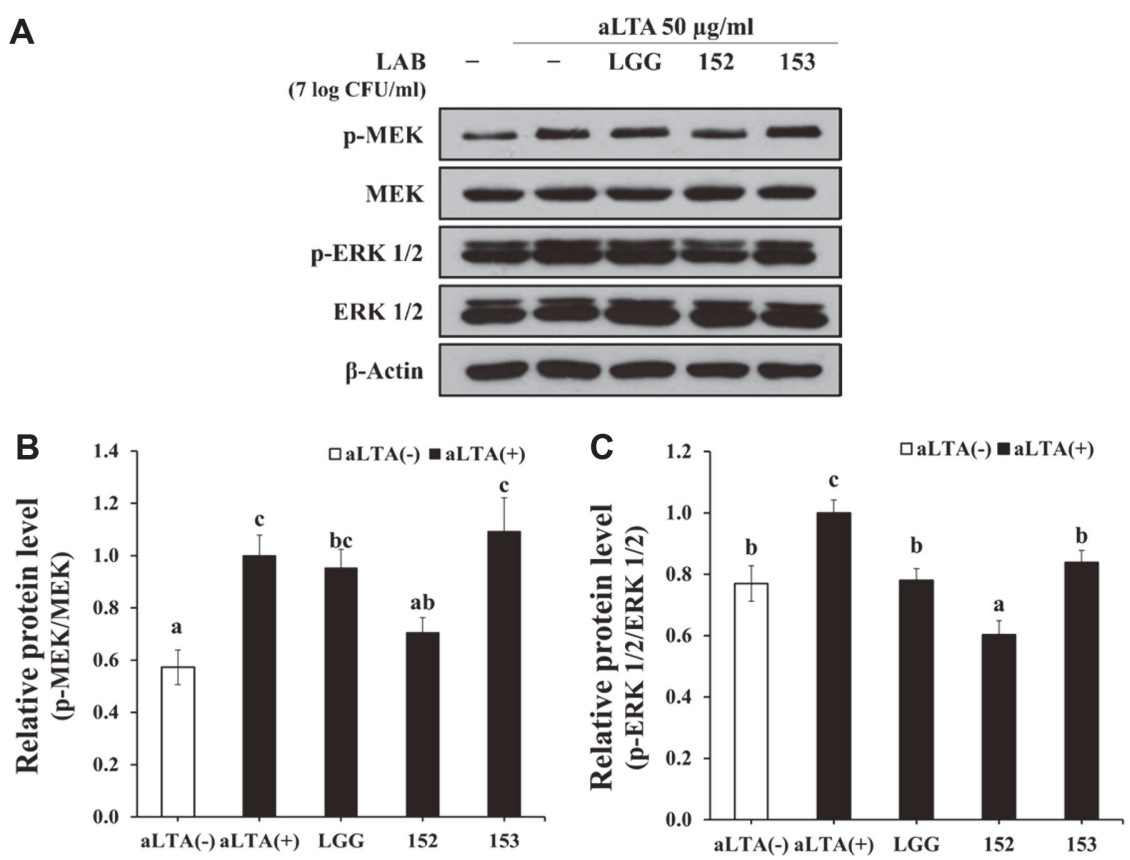

Fig. 3. Modulatory effect of Lactobacillus strains on MEK/ERK signaling pathways in HT-29 cells. Fully confluent cells were pretreated with $7 \log \mathrm{CFU} / \mathrm{ml}$ of Lactobacillus strains for $2 \mathrm{~h}$ and stimulated with $50 \mu \mathrm{g} / \mathrm{ml}$ aLTA for $20 \mathrm{~min}$. A. Expression of phosphorylation of MEK and ERK 1/2 assessed using western blotting. B, C. Relative expression levels of phosphorylated MEK and ERK 1/2 quantified using the ImageJ software. Different letters indicate statistical differences $(p<0.05)$.

A
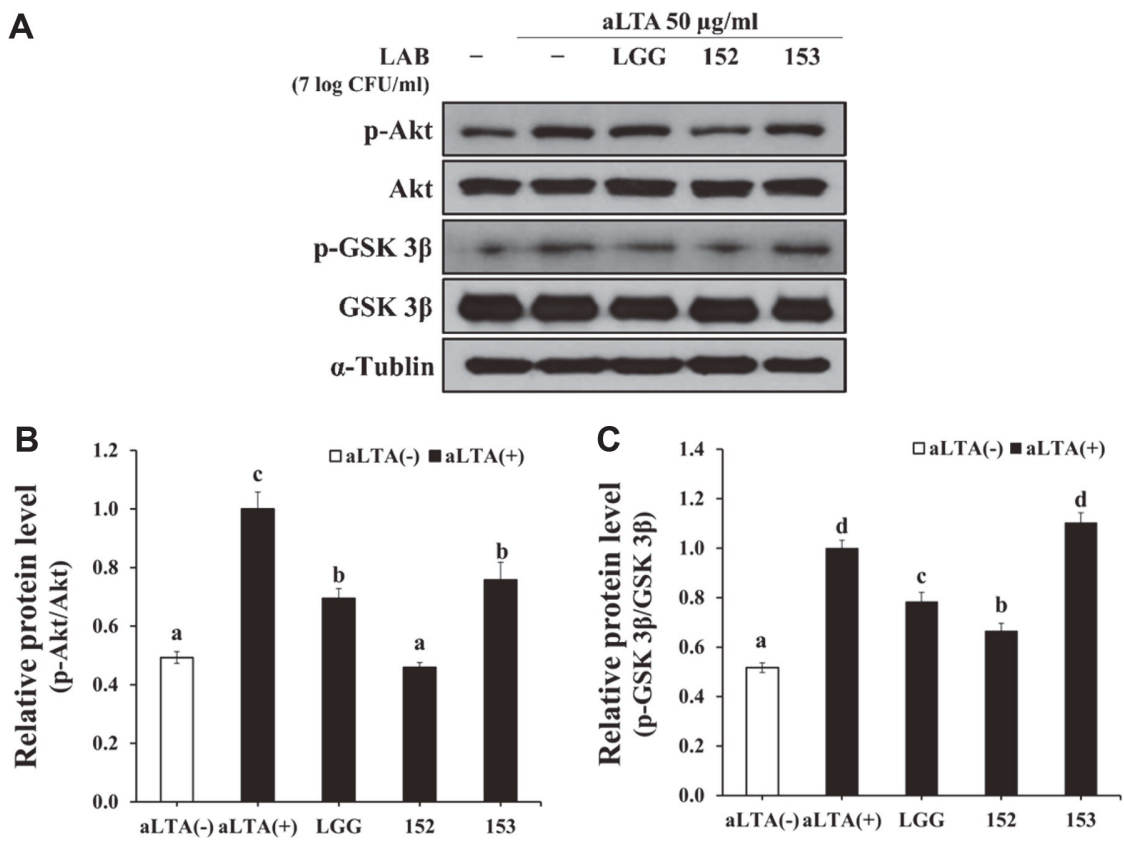

Fig. 4. Regulatory effect of Lactobacillus strains on Akt/GSK $3 \beta$ signaling pathways in HT-29 cells. HT-29 cell monolayers were pretreated with various Lactobacillus strains, followed by aLTA stimulation for $10 \mathrm{~min}$. A. Effect of Lactobacillus strains on the activation of Akt/GSK $3 \beta$ signaling pathways. B, C. Relative expression levels of phosphorylated Akt and GSK $3 \beta$. Different letters indicate statistical differences $(p<0.05)$. 
Effect of L. brevis KU15152 on Akt/GSK $3 \beta$ Signaling Pathways in HT-29 Cells

IL- 8 is reportedly associated with the activation of Akt, which leads to phosphorylation of GSK $3 \beta$. As shown in Fig. 4, aLTA stimulation promoted the phosphorylation of Akt. Treatment with L. brevis KU15152 reduced the phosphorylation of Akt induced by aLTA. The aLTA-induced activation of GSK $3 \beta$ was mitigated by L. brevis KU15152. These findings indicate that L. brevis KU15152 can suppress inflammatory responses in intestinal epithelial cells by regulating the Akt/GSK $3 \beta$ signaling pathways.

\section{Discussion}

Probiotics are used to maintain and improve human health. To function as probiotics, LAB strains should survive the transit through the gastrointestinal tract and adhere to the intestine for a certain period [19]. In the present study, we demonstrated that L. brevis KU15152 had a high survival rate of $99.36 \%$ after incubation at $\mathrm{pH}$ 2.5 for $3 \mathrm{~h}$. The tolerance to the gastrointestinal conditions of low $\mathrm{pH}(\mathrm{pH} 2.5-3.5)$ is essential for probiotic strains, because they must go through the stomach [20]. The $\mathrm{pH}$ of gastric acid is usually 2.5, which can disrupt the bacterial cell envelope. Bile has a bacteriostatic role within the gut, and its effects are regulated by bile salts. However, bile salts can damage the structure of the bacterial cell membrane and kill bacteria [21]. The present study findings demonstrated the capability of L. brevis KU15152 to survive under condition mimicking bile salt with essentially no decline in viability after incubation in MRS broth with $0.3 \%$ oxgall for $24 \mathrm{~h}$. These results are comparable with those of a previous study on the probiotic characteristics of L. brevis strains [15]. Furthermore, bile salt hydrolase produced by Lactobacillus bacteria increases the number of viable bacteria after incubation with bile salts [22]. As previously reported, probiotic organisms compete with pathogens for binding sites in the intestine, and for probiotics, intestinal adhesion is an important criterion [23]. L. brevis KU15152 and LGG exhibited adhesion rates of $12.92 \%$ and $12.04 \%$, respectively. Compared with the adhesion abilities of various probiotic strains in a previous study [24], L. brevis KU15152 avidly adhered to intestinal epithelial cells. The strain produced various enzymes but did not produce hazardous enzymes including $\beta$-glucuronidase. These results indicate the likelihood that L. brevis KU15152 can survive in the human gastrointestinal tract and function as a probiotic.

LTA from $S$. aureus stimulates host cells to produce inflammatory cytokines such as IL-8 and tumor necrosis factor- $\alpha$ by the activation of NF- $\kappa B[25,26]$. LTAs from pathogenic bacteria, including S. aureus, S. epidermidis, and Streptococcus pneumonia could activate macrophages. In contrast, LTAs from probiotics and non-pathogenic bacteria, such as L. plantarum, have weak immunostimulatory effects [27]. In the present study, $50 \mu \mathrm{g} / \mathrm{ml}$ aLTA stimulated the secretion of IL-8 from HT-29 cells following NF- $\kappa$ B activation, and L. brevis KU15152 had an inhibitory effect on this activation. IL- 8 is a chemokine that attracts leukocytes, such as basophils and neutrophils, to lesions and is associated with angiogenesis, metastasis, and inflammation [28]. After proinflammatory stimulation, a signaling cascade begins, leading to the translocation of NF- $\mathrm{kB}$ into the nucleus. In a previous study, decreased IL-8 production after glutamine pretreatment in human intestinal epithelial cells was accompanied by a

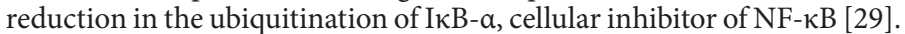

In epithelial cells, Chlamydia trachomatis infection upregulates IL-8 secretion through the ERK signaling pathway [30,31]. MEK1 and MEK2 are associated with the regulation of cellular processes [32]. MEK plays a role in the initiation of the MEK/ERK pathway. In addition, ERK 1/2 reacts with various substrates in the cytoplasm and nucleus and activated ERK catalyzes the activation of transcription factors, which results in the expression of several genes related to cell differentiation, proliferation, and apoptosis [33]. In the present study, the expression levels of phosphorylated MEK and ERK 1/2 increased in aLTA-stimulated HT-29 cells compared to those in the aLTA-negative group. L. brevis KU15152 pretreatment downregulated such expression.

The binding of IL-8 to its receptors activates the Akt signaling pathway [34]. Akt can activate B-cell lymphomarelated X protein and decrease mitochondrial membrane translocation and apoptosis [35]. Akt phosphorylates GSK $3 \beta$, which is important in cell death. For example, increased phosphorylated GSK $3 \beta$ can cause apoptosis in neuronal PC12 cells and fibroblasts [36]. Furthermore, ginsenoside Rg1 modulates innate immune responses by regulating the PI3K/Akt pathway [37]. In the present study, pretreatment with L. brevis KU15152 reduced the extent of phosphorylation of Akt and GSK $3 \beta$ induced by aLTA in intestinal epithelial cells.

In conclusion, this study demonstrates the anti-inflammatory potential and probiotic characteristics of $L$. brevis KU15152 using the representative intestinal epithelial cells, HT-29. L. brevis KU15152 tolerated artificial gastric acid and bile salts, and avidly adhered to HT-29 cells. L. brevis KU15152 alleviated aLTA-induced IL-8 production by suppressing NF- $\kappa B$ activation. The inhibitory effect of L. brevis KU15152 on intestinal inflammatory response was mediated by the regulation of MEK/ERK and Akt/GSK $3 \beta$ signaling pathways. Although further studies are required, these findings provide underlying molecular evidence for the protective effects of probiotics on the intestine. The collective findings indicate the potential of L. brevis KU15152 as a functional probiotic product.

\section{Acknowledgments}

This work was supported by the Korea Institute of Planning and Evaluation for Technology in Food, Agriculture and Forestry (IPET) through the High Value-added Food Technology Development Program, funded by the Ministry of Agriculture, Food and Rural Affairs (MAFRA) (\#321035-5).

\section{Conflict of Interest}

The authors have no financial conflicts of interest to declare. 


\section{References}

1. Conlon MA, Bird AR. 2015. The impact of diet and lifestyle on gut microbiota and human health. Nutrients 7: 17-44.

2. Mendes V, Galvao I, Vieira AT. 2019. Mechanisms by which the gut microbiota influences cytokine production and modulates host inflammatory responses. J. Interferon Cytokine Res. 39: 393-409.

3. Issac Ginsburg. 2002. Role of lipoteichoic acid in infection and inflammation. Lancet Infect. Dis. 2: 171-179.

4. Jeong JH, Jang S, Jung BJ, Jang KS, Kim BG, Chung DK, et al. 2015. Differential immunue-stimulatory effects of LTAs from different lactic acid bacteria via MAPK signaling pathway in RAW 264.7 cells. Immunobiol. 220: 460-466.

5. Shokryazdan P, Sieo CC, Kalavathy R, Liang JB, Alitheen NB, Faseleh Jahromi M, et al. 2014. Probiotic potential of Lactobacillus strains with antimicrobial activity against some human pathogenic strains. Biomed. Res. Int. 2014: 927268-927216.

6. Jiang Y, Li L, Sun H, Shan Y, Liu Y, Li L, et al. 2016. Induction of cytokines via NF-kB and p38 MAP kinase signaling pathways associated with the immunomodulation by Lactobacillus plantarum NDC 75017 in vitro and in vivo. J. Func. Foods 20: 215-225.

7. Gupta T, Kaur H, Kapila S, Kapila R. 2021. Lactobacillus fermentum (MTCC-5898) alleviates Escherichia coli-induced inflammatory responses in intestinal epithelial cells by modulating immune genes and NF-кB signaling. J. Appl. Microbiol. https://doi: 10.1111/jam.15153.

8. Li X, Hu D, Tian Y, Song Y, Hou Y, Sun L, et al. 2020. Protective effects of a novel Lactobacillus rhamnosus strain with probiotic characteristics against lipopolysaccharide-induced intestinal inflammation in vitro and in vivo. Food Funct. 11: 5799.

9. Song MW, Chung Y, Kim KT, Hong WS, Chang HJ, Paik HD. 2020. Probiotic characteristics of Lactobacillus brevis B13-2 isolated from kimchi and investigation of antioxidant and immune-modulating abilities of its heat-killed cells. LWT-Food Sci. Technol. $128: 109452$.

10. Yu HS, Lee NK, Choi AJ, Choe JS, Bae CH, Paik HD. 2019. Antagonistic and antioxidant effect of probiotic Weissella cibaria JW15. Food Sci. Biotechnol. 28: 851-855.

11. Kim KT, Yang SJ, Paik HD. 2021. Probiotic properties of novel probiotic Levilactobacillus brevis KU15147 isolated from radish kimchi and its antioxidant and immune-enhancing activities. Food Sci. Biotechnol. 30: 257-265.

12. Yu HS, Lee NK, Choi AJ, Choe JS, Bae CH, Paik HD. 2019. Anti-inflammatory potential of probiotic strain Weissella cibaria JW15 isolated from kimchi through regulation of NF- $\mathrm{kB}$ and MAPKs pathways in LPS-induced RAW 264.7 cells. J. Microbiol. Biotechnol. 29: $1022-1032$.

13. Kim H, Kim HS, Park WJ, Chung DK. 2015. Inhibitory effect of Lactobacillus plantarum extracts on HT-29 colon cancer cell apoptosis induced by Staphylococcus aureus and its alpha-toxin. J. Microbiol. Biotechnol. 25: 1849-1855.

14. Li SC, Hsu WF, Chang JS, Shih CK. 2019. Combination of Lactobacillus acidophilus and Bifidobacterium animalis subsp. lactis shows a stronger anti-inflammatory effect than individual strains in HT-29 cells. Nutrients 11: 969.

15. Jang HJ, Lee NK, Paik HD. 2019. Probiotic characterization of Lactobacillus brevis KU15153 showing antimicrobial and antioxidant effect isolated from kimchi. Food Sci. Biotechnol. 28: 1521-1528.

16. Yu HS, Jang HJ, Lee NK, Paik HD. 2019. Evaluation of the probiotic characteristics and prophylactic potential of Weissella cibaria strains isolated from kimchi. LWT-Food Sci. Technol. 112:108229.

17. Kim WJ, Yu HS, Bae WY, Ko KY, Chang KH, Lee NK, et al. 2021. Chrysanthemum indicum suppresses adipogenesis by inhibiting mitotic clonal expansion in 3T3-L1 preadipocytes. J. Food Biochem. 45: e13896.

18. Yu HS, Kim WJ, Bae WY, Lee NK, Paik HD. 2020. Inula britannica inhibits adipogenesis of 3T3-L1 preadipocytes via modulation of mitotic clonal expansion involving ERK $1 / 2$ and Akt signaling pathways. Nutrients 12: 3037.

19. Yang SJ, Kim KT, Kim TY, Paik HD. 2020. Probiotic properties and antioxidant activities of Pediococcus pentosaceus SC28 and Levilactobacillus brevis KU15151 in fermented black gamju. Foods 9: 1154.

20. Singh S, Bhatia R, Singh A, Singh P, Kaur R, Khare P, et al. 2018. Probiotic attributes and prevention of LPS-induced proinflammatory stress in RAW264.7 macrophages and human intestinal epithelial cell line (Caco-2) by newly isolated Weissella cibaria strains. Food Func. 9: 1254.

21. Bao Y, Zhang Y, Zhang Y, Liu Y, Wang S, Dong X, et al. 2010. Screening of potential probiotic properties of Lactobacillus fermentum isolated from traditional dairy products. Food Control 21: 695-701.

22. Guo CF, Zhang S, Yuan YH, Yue TL, Li JY. 2015. Comparison of lactobacilli isolated from Chinese suan-tsai and koumiss for their probiotic and functional properties. J. Funct. Foods 12: 294-302.

23. Argyri AA, Zoumpopoulou G, Karatzas KAG, Tsakalidou E, Nychas GJE, Panagou EZ, et al. 2013. Selection of potential probiotic lactic acid bacteria from fermented olives by in vitro tests. Food Microbiol. 33: 282-291.

24. Lee CS, Kim SH. 2020. Anti-inflammatory and anti-osteoporotic potential of Lactobacillus plantarum A41 and L. fermentum SRK414 as probiotics. Probiotics Antimicrob. Proteins 12: 623-634.

25. Kim HG, Lee SY, Kim NR, Ko MY, Lee JM, Yi TH, et al. 2008. Inhibitory effects of Lactobacillus plantarum lipoteichoic acid (LTA) on Staphylococcus aureus LTA-induced tumor necrosis factor-alpha production. J. Microbiol. Biotechnol. 18: 1191-1196.

26. Wang J, Qi L, Wu Z, Mei L, Wang H. 2016. Different effects of lipoteichoic acid from C. butyricum and S. aureus on inflammatory responses of HT-29 cells. Int. J. Biol. 87: 481-487.

27. Kim H, Jung BJ, Jung JH, Kim JY, Chung SK, Chung DK. 2012. Lactobacillus plantarum lipoteichoic acid alleviates TNF- $\alpha$-induced inflammation in the HT-29 intestinal epithelial cell line. Mol. Cells 33: 479-486.

28. Singh S, Singh AP, Sharma B, Owen LB, Singh RK. 2010. CXCL8 and its cognate receptors in melanoma progression and metastasis. Future Oncol. 6: 111-116.

29. Hubert-Buron A, Leblond J, Jacquot A, Ducrotte P, Dechelotte P, Coeffier M. 2006. Glutamine pretreatment reduces IL-8 production in human intestinal epithelial cells by limiting IкBa ubiquitination. J. Nutr. 136: 1461-1465.

30. Buchholz KR, Stephens RS. 2008. The cytosolic pattern recognition receptor NOD1 induces inflammatory interleukin-8 during Chlamydia trachomatis infection. Infect. Immun. 76: 3150-3155.

31. Fernandes AF, Bian Q, Jiang JK, Thomas CJ, Taylor A, Pereira P, et al. 2009. Proteasome inactivation promotes p38 mitogen-activated protein kinase-dependent phosphatidylinositol 3-kinase activation and increases interleukin-8 production in retinal pigment epithelial cells. Mol. Biol. Cell 16: 3690-3699.

32. Zhu L, Dai LM, Shen H, Gu PQ, Zheng K, Liu YJ, et al. 2019. Qing Chang Hua Shi granule ameliorate inflammation in experimental rats and cell model of ulcerative colitis through MEK/ERK signaling pathway. Biomed. Pharmacother. 116: 108967.

33. Kohno M, Tanimura S, Ozaki K. 2011. Targeting the extracellular signal-regulated kinase pathway in cancer therapy. Biol. Pharm. Bull. 12: 1781-1784.

34. Long X, Ye Y, Zhang L, Liu P, Yu W, Wei F, et al. 2016. IL-8, a novel messenger to cross-link inflammation and tumor EMT via autocrine and paracrine pathways (review). Int. J. Oncol. 48: 5-12.

35. Son YO, Pratheeshkumar P, Wang L, Fan J, Kim DH, Lee JY, et al. 2013. Reactive oxygen species mediate Cr(VI)-induced carcinogenesis through PI3K/AKT-dependent activation of GSK-3 $\beta / \beta$-catenin signaling. Toxicol. Appl. Pharmacol. 271: 239-248.

36. Maurer U, Preiss F, Brauns-Schubert P, Schlicher L, Charvet C. 2014. GSK-3-at the crossroads of cell death and survival. J. Cell. Sci. 127: 1369-1378.

37. Zhang Y, Zhang Z, Wang H, Cai N, Zhou S, Zhao Y, et al. 2016. Neuroprotective effect of ginsenoside Rg1 prevents cognitive impairment induced by isoflurane anesthesia in aged rats via antioxidant, anti-inflammatory and anti-apoptotic effects mediated by the PI3K/AKT/GSK-3ß pathway. Mol. Med. Rep. 14: 2778-2784. 